S. H. SEO, ${ }^{1}$ Ch. K. LEE, ${ }^{2}$ and S. K. YOO ${ }^{3}$

\title{
NEURAL CORRELATES RELATED TO ANXIETY IN ATTENTIONAL INHIBITION CONTROL: AN ERP STUDY
}

\author{
Received September 12, 2013
}

We investigated the effect of anxiety on attentional inhibitory control using event-related potentials (ERPs) and measuring the response time. Nineteen participants performed a multisource interference task; three-digit numbers and emotional faces were used as visual stimuli. The P100 and P300 ERP-components and response time values were used to evaluate whether ERP parameters and behavioral responses are associated with increased anxiety. Higher anxiety was associated with a longer latency and reduced amplitude of the P300 component at F3, whereas higher anxiety was associated with a shorter latency and higher amplitude of P300 at F4. The longer P300 latency at F3 was especially related to the response time to the target number with negative-expression faces as distracters.

Keywords: anxiety, attentional inhibitory control, event-related potentials (ERPs), multi-source interference task.

\section{INTRODUCTION}

Existing evidence indicates that high anxiety is often associated with impaired performance in various cognitive tasks $[1,2]$. A variety of models have been proposed to account for this deficit [3]. An attentional control theory [1] posits that high anxiety adversely affects central executive functions such as inhibition and attention shifting. The above-mentioned functions play a key role in selfregulation; deficits in the executive functioning are identified as a fundamental component in a variety of developmental psychopathologies, including attention deficit hyperactivity disorder, conduct disorder, and substance abuse [4, 5]. Inhibition is an important regulatory function that uses attentional control to suppress attentional resources directed to taskirrelevant stimuli.

Most research on the effects of anxiety on inhibitory control has compared task performances under low and high distraction conditions [1]. Research on anxiety and inhibitory control is based on several

\footnotetext{
${ }^{1}$ Department of Computer Engineering, Kyungnam University, Changwon, Republic of Korea.

${ }^{2}$ Center for Bionics, Korea Institute of Science and Technology, Seoul, Republic of Korea.

${ }^{3}$ Department of Medical Engineering, College of Medicine, Yonsei University, Seoul, Republic of Korea.

Correspondence should be addressed to S. K. Yoo

(e-mail: shseotwin@kyungnam.ac.kr, chungki@kist.re.kr, sunkyoo@yuhs.ac)
}

assumptions. First, high anxiety should impair the processing efficiency whether the distracting stimuli are task-irrelevant ones presented by the experimenter or induced by worrying thoughts. Generally, the performance effectiveness can be defined as the quality of performance, and the processing efficiency can be defined as the relationship between the performance effectiveness and spending of resources or efforts. The processing efficiency is high when performance effectiveness is high, while the use of resources is low. Eysenck and Derakshan [6] have suggested that anxiety typically impairs the processing efficiency to a greater extent than the performance effectiveness. Second, the adverse effects of anxiety under distraction conditions are greater when the task-irrelevant stimuli are threatrelated rather than neutral. In several studies, it was suggested that anxious individuals have an attentional bias for threat-related stimuli, and that they have more difficulties in disengaging attention from such stimuli [7]. Further, recent research has demonstrated that anxiety can influence inhibitory control even in the absence of threat $[8,9]$.

Assumptions about attentional inhibitory control have been tested to obtain direct estimates of such control using various tasks. Derakshan [10] found, using the antisaccade task [11] that involved the measurement of eye movements, that high-anxiety vs. low-anxiety individuals demonstrated significantly longer antisaccade latencies. Additionally, as was found in other studies, high-anxiety individuals 
had longer antisaccade latencies in response to the inhibited target. Ansari [12] also found that highly anxious individuals have lower ERP activity in the period prior to onset of the inhibited target on antisaccade trials.

Several studies have also investigated the effects of anxiety on inhibition of attention toward distracting stimuli. As was found [13], angry facial expressions are detected faster in a crowd of happy expressions, whereas happy face targets were the slowest to be detected in a crowd of angry faces using a visual search task [14], suggesting that fear-motivated processing may occur more rapidly than non-fear processing. Additionally, Fox $[15,16]$ found that individuals with a high-anxiety state took a significantly longer time to disengage attention from an angry face compared to those with low anxiety in an emotional spatialcuing task. Neuroimaging studies also demonstrated that highly trait-anxious individuals showed a reduced prefrontal activity and a slowed target identification response when the task did not fully occupy the attentional resources in a letter-search task [9]. This research suggests that trait anxiety may be linked to reduced activation of the prefrontal attentional control mechanisms that inhibit distracter processing, even when threat-related stimuli are absent. Taken together, these findings provide evidence for the assumption that anxiety impairs the processing efficiency and inhibitory control.

Neurocognitive models of executive attentional control implicate the lateral prefrontal cortex (PFC), including the dorsolateral and ventrolateral PFCs (DLPFC and VLPFC, respectively), as well as the anterior cingulate cortex (ACC), which are involved in executive attentional control, particularly in the allocation of resources during a conflicting or distracting situations [17-19]. The involvement of the DLPFC related to attentional control was demonstrated through a task-manipulating response conflict, where task-irrelevant stimuli promote a response required by the current target [20,21].

There are many studies where the effects of anxiety on cognitive performance were estimated. However, the data for research assessing the relationship between anxiety and inhibitory attentional control with emotional distracters are scarce. Further, a few studies examined the relationship between anxiety and attentional control using direct measures such as parameters of event-related potentials (ERPs) and functional magnetic resonance imaging (fMRI). It is important to understand the neural mechanisms involved when anxiety impairs the effective inhibitory control. Previous studies typically examined the processing efficiency using behavioral measures. Accordingly, our present study aimed to address this critical gap in the literature.

We used a modified Multi-Source Interference Task (MSIT, [22]) to assess attentional inhibitory control related to anxiety. This task is a top-down control task of selective attention, where a target number and a distracter (an image of the emotional facial expression) are presented. In behavioral studies, it was found that faces capture attention more readily than other visual stimuli such as pictures of musical instruments or appliances [23]. In particular, faces displaying a negative affect vs. neutral or happy faces capture attention differentially [24]. Ebner [25] showed that task-irrelevant faces increase the response time in face-unrelated number trials using the MSIT. Task-irrelevant faces also disrupt responses to faceunrelated targets. Thus, we believe that the MSIT is a valid method of assessing attentional inhibitory control because attention is required to select the target number, and inhibition is required to ignore the task-irrelevant face.

The goal of our study was to understand how anxiety impairs efficient inhibition control by assessing neural mechanisms using direct measures (such as ERP parameters) and to correlate this neural measure with the behavioral response. We hypothesized several outcomes. First, anxiety would be correlated with cortical activity in the prefrontal regions (such as the DLPFC) within the MSIT period. Second, higher anxiety would be related to longer latencies of the ERP components and longer response times due to slowed target identification. Third, higher anxiety would be associated with enhanced neural activation in order to achieve a given level of the cognitive task performance.

\section{METHODS}

Participants. Nineteen right-handed graduates (10 men and 9 women; mean age 30 years) from the Yonsei University participated in the study. All participants were free from psychiatric or neurological disorders. Data from three participants were excluded because of excessive artifacts in the ERP data, leading to a final sample of 54 .

Participants completed the Korean version of the State-Trait Anxiety Inventory (STAI, [26, 27]) prior 
to every session.

Multi-Source Interference Task. This task was a modified version of the Multi-Source Interference Task (MSIT, [22]). Participants were instructed to maintain fixation on the center of a cross presented on the monitor. A pair of face and number stimuli (three digits around the nose area of the emotional face) was presented for $1500 \mathrm{msec}$. Each pair consisted of three numbers and one emotional face image. Pictures were selected from the FACES 3.3.1 database at the Max Planck Institute for Human Development (MPIB; FACES ID: ssanghee) [28]. The pictures contained a set of images of naturalistic faces of 144 young men with each one displaying one of the following six facial expressions, namely neutrality, sadness, disgust, fear, anger, and happiness. Three digits, two matching and one nonmatching, were presented, and the digit that differed was the target number. Next, a gray screen with the fixation cross was presented for $1500 \mathrm{msec}$.

Participants completed three sessions that were conducted at the same time of day over the course of three consecutive days. After taking a 10-min break with their eyes open, the task was presented for 3 min to familiarize participants with the protocol prior to the start of the experiment. As illustrated in Fig. 1, 144 fixation crosses and 144 pictures ( 6 facial types presented 24 times) were each presented for a period of $1.5 \mathrm{sec}$ randomly during the experiment. The three numbers (e.g., 1, 2, and 3) were presented randomly against the background of the emotional face. For example, if 232 was presented, the digit 3 would be the target number. Participants were asked to press the target button using a number keypad (made in the laboratory). For each participant, the response time to press the target button was measured. Errors included incorrect key pressing, missed key presses, or a response time $>1500 \mathrm{msec}$.

EEG Recording and Data Reduction. EEG was continuously recorded for each participant during the task. Recording electrodes were positioned according to the international 10-20 system of electrode placement, including the earlobes. A ground electrode was placed on the back of the neck (Iz), whereas reference electrodes were placed on the right and left ears (A1+A2). The use of two linked earlobes as a reference conceptually provides a virtual reference site in the middle of the head. The use of symmetrical reference sites provides avoiding bias recordings toward activity in one hemisphere [29]. Eye movement artifacts were corrected using the ICA algorithm. All electrode impedances were below $5 \mathrm{k} \Omega$. The EEG signals were amplified using a Biopac MP150 TM system, band-pass filtered $(0.1-100 \mathrm{~Hz})$, and digitized at a sampling rate of $1000 \mathrm{sec}^{-1}$. The high-pass and low pass filters for EEG signals were set to 0.5 and $100 \mathrm{~Hz}$, respectively. The $60 \mathrm{~Hz}$ notch filter was continuously in use. Values of the amplitudes of ERP components were obtained by stimulus-locked averaging from 0 to $1000 \mathrm{msec}$ after baseline correction.

Primary ERP analysis was focused on the P100 and P300 components. The P100 is sensitive to visual spatial attention toward emotional faces [30], and the P300 component is associated with number identification because this component is closely related to the selective attentional requirements of target identification [31]. Thus, the P100 (100-200 msec) and P300 (250-450 msec) components were compared by analyzing the mean amplitudes and peak latencies of these waves at the F3, F4, Cz, and Pz positions after stimulus onset.

Statistical Analyses. To test DLPFC and ACC involvement related to attentional inhibitory control during MSIT, Pearson's correlation analysis between P100 and P300 components was performed. To test the effects of anxiety on attentional inhibitory control, the dependence between ERP parameters and anxiety state was estimated using multiple regression where the relationships of the state of anxiety (STAI score) to each of the P100 amplitude, P300 amplitude, P100 latency, and P300 latency at each position (e.g., F3, $\mathrm{F} 4, \mathrm{Cz}$, and $\mathrm{Pz}$ ) were examined. Also, to determine the relationship between ERP indices and behavioral responses, the relationship between the response time
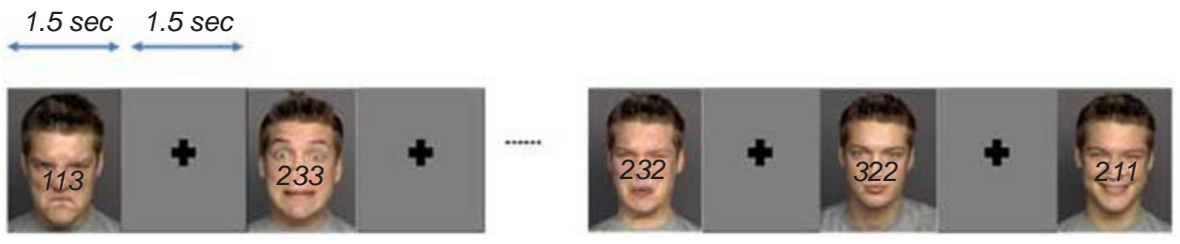

7 (min)
F i g. 1. Schematic representation of the experimental design; participants were instructed to press a keypad button at target number as soon as possible.

Р и с. 1. Схема експерименту; тестовані були інструктовані якнайшвидше натиснути кнопку при пред'явленні цільового числа.

Total 144 images, 144 cross 
with the face type presented and ERP parameters was tested using multiple regression analysis. Multiple regression analysis was also used to examine the relationship between ERP responses and the number of errors. All statistical analyses were carried out using SPSS 16.0 (SPSS Inc., USA).

\section{RESULTS}

ERP Responses to the Multi-Source Interference Task. Attentional control has been mentioned as an available mechanism that may mediate difficulties in disengagement of attention from a threat or emotional distracter [1]. Two stages of information processing, automatic and strategic, are required under such conditions [32, 33]. Automatic processing refers to processing that occurs without intent, control, or awareness, whereas strategic processing refers to that which is intentional, controllable, and dependent on awareness. The MSIT requires combined information processing (both automatic and strategic) with respect to the facial expression (automatic) and target identification (strategic).The ERP responses at presentations of target numbers and facial expressions are shown in Fig. 2. Because facial expression receives high attentional priority, the early-emerging P100 peak appears to be related to presentation of the taskirrelevant facial expression, while the later-emerging P300 peak appears to be associated with identification of the target number.

ERP Responses and Attentional Inhibitory Control Influenced by Anxiety. The purpose of this analysis was to determine: (i) whether the MSIT is a valid task for assessing emotion-related attentional inhibitory control, and (ii) whether the ERP P300
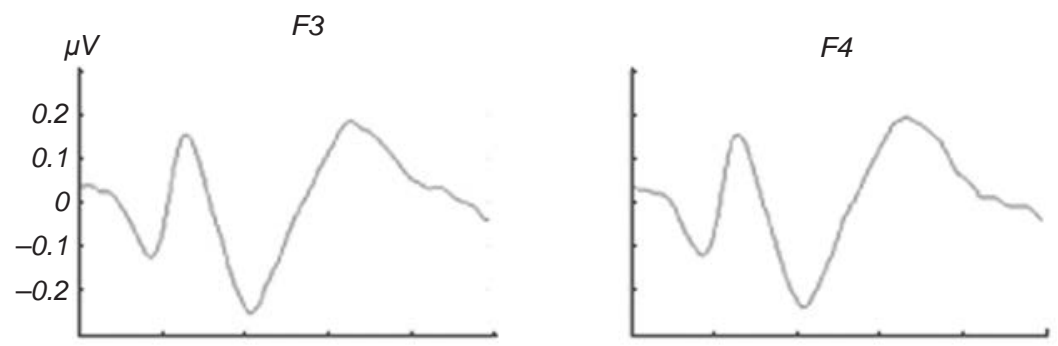

F i g. 2. ERP waveforms induced by emotional facial expression and target number.

Р и с. 2. Форми хвиль пов'язаних із подією потенціалів, індукованих пред'явленням зображень облич $з$ емоціональними виразами та цільових чисел.
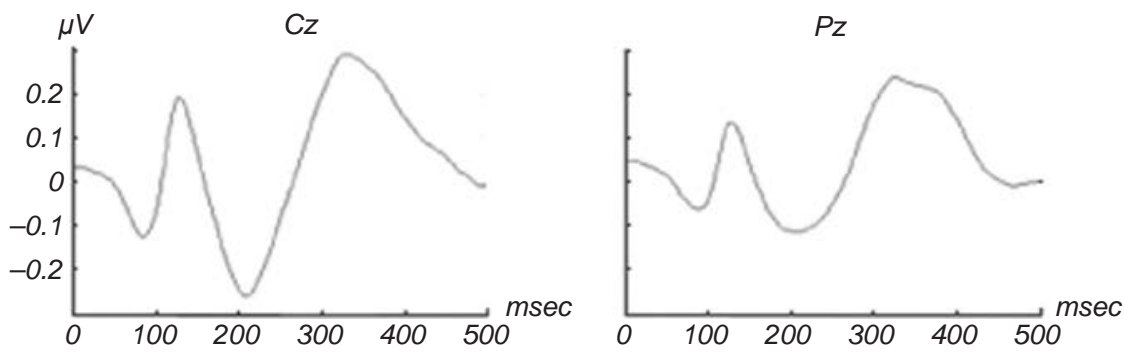

Table 1. Correlation scores between the P100 and P300 ERP components

Т а б л и ц я 1. Кореляція між характеристиками компонентів Р100 та Р300 в складі пов'язаних із подісю потенціалів

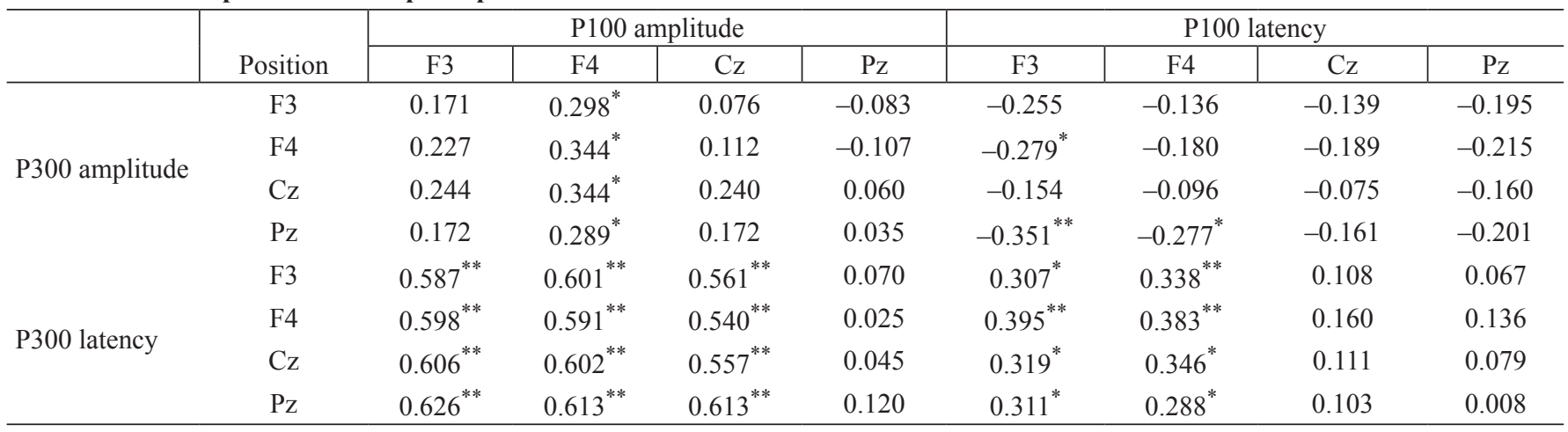

Footnote: ${ }^{* *} P<0.01,{ }^{*} P<0.05$ 
component specifically reflects emotion-related attentional inhibitory control related to the anxiety level. The DLPFC and ACC may be neural mechanisms responsible for difficulties in disengaging attention from an emotional distracter. Table 1 shows the correlation between parameters of the P100 component to facial expression and those of the P300 component related to target identification. The P100 amplitudes and latencies at F3 and F4 demonstrated positive correlations with the $\mathrm{P} 300$ latencies at all positions. The F3 and F4 sites correspond to the DLPFC area. In addition, this result shows that the greater the neural activation induced by facial expression, the greater the ERP latency related to target identification.

To test whether the ERP latency to the target number predicts inhibitory control related to anxiety under MSIT conditions, multiple regression analysis was performed using a backward method, where the P100 and P300 latency at each position (in particular, $\mathrm{F} 3, \mathrm{~F} 4, \mathrm{Cz}$, and $\mathrm{Pz}$ ) served as predictors, and the STAI score served as the dependent variable. If the relationship between the ERP latency in the DLPFC region (at F3 and F4 leads) and the anxiety level is significant, the MSIT could be regarded as a valid task. In particular, the P300 latency could be a neural factor that reflects the delay in target identification, suggesting that anxiety-related executive control failed to inhibit attention to task-irrelevant face images. The results showed that higher anxiety was associated with increased awareness of task-irrelevant faces (Table 2a), and that participants with a longer P300 latency in F3 and a shorter P300 latency in F4 reported higher anxiety levels (Table $2 \mathrm{~b}$ ). The regression models of the P100 $(F=15.285, d f=1, P<0.001)$ and the P300 $(F=6.452, d f=3, P=0.001)$ latencies were both statistically significant, while the $\mathrm{Cz}$ latency of the P300 component did not reach the statically significant level $(P>0.05)$. Negative (although weak) correlation between the P100 Pz latency and the STAI was observed $(r=-0.195)$, suggesting that the higher the anxiety state, the shorter the P100 latency at Pz, indicating faster processing of emotional face images. Additionally, the relationships of the F3 latency $(r=0.250)$ and F4 latency $(r=-0.210)$ with the STAI score were also significant. Thus, the correlation coefficient for the F3 latency was positive, indicating that the longer the F3 latency, the higher the STAI score. At the same time, the coefficient for the F4 latency was negative, suggesting that the shorter the F4 latency, the higher the STAI score. Thus, opposite characteristics of the P300 latency in two DLPFC regions were associated with higher anxiety. Consistent with predictions, the MSIT could be used to evaluate the association between neural activation in the DLPFC area and the state of anxiety.

Behavioral Responses Related to Attentional Inhibitory Control. Behavioral data were analyzed to determine whether a longer ERP latency is accompanied by slower target identification. We analyzed the relationship between the ERP latency and response time to target identification. Additionally, we tested a supposition that the type of facial expression used as a distractor would affect target identification. Multiple regression was used for averaged values of the response time as the dependent variable and the F3, F4, Cz, and Pz latencies of the P300 component as predictors. The averaged response time was defined as the mean of the response times to all types of target

Table 2. Associations of the STAI score with ERP latency variables using multiple linear regression analysis

T а б л и ц я 2. Зв'язки між оцінками за STAI та латентними періодами компонентів пов'язаних із подісю потенціалів, визначені з використанням аналізу множинної лінійної регресії

(a) Latency of the P100 component

\begin{tabular}{l|c|c}
\hline Variable & $\mathrm{M} \pm$ s.e.m. & $P$ value \\
\hline Pz latency & $-0.195 \pm 0.05$ & 0.000 \\
\hline
\end{tabular}

(b) Latency of the P300 component

\begin{tabular}{l|c|c}
\hline \multicolumn{1}{c|}{ Variable } & $\mathrm{M} \pm$ s.e.m. & $P$ value \\
\hline F3 latency & $0.250 \pm 0.067$ & 0.000 \\
F4 latency & $-0.210 \pm 0.066$ & 0.002 \\
Cz latency & $-0.083 \pm 0.045$ & 0.071 \\
\hline
\end{tabular}

Footnotes: s.e.m. are the standard errors; dependent variable is STAI score 
Table 3. Associations of the response time to the face type using multiple regression analysis

Т а б л и ц я 3. Зв'язки між часом реакції та типом виразу обличчя, визначені з використанням аналізу множинної лінійної регресії

\begin{tabular}{|c|c|c|c|c|c|c|c|c|}
\hline \multirow{2}{*}{$\begin{array}{c}\text { Variable } \\
\text { Type of face }\end{array}$} & \multicolumn{2}{|c|}{ F3 latency } & \multicolumn{2}{|c|}{ ANOVA } & \multicolumn{2}{|c|}{ F4 latency } & \multicolumn{2}{|c|}{ ANOVA } \\
\hline & $\mathrm{M} \pm$ s.e.m. & $P$ value & $F$ & $P$ value & $M \pm$ s.e.m. & $P$ value & $F$ & $P$ value \\
\hline Annoy & $0.767 \pm 0.263$ & 0.005 & 8.512 & 0.005 & $\mathrm{NS}$ & & & \\
\hline Disgust & $0.636 \pm 0.254$ & 0.015 & 6.286 & 0.015 & NS & & & \\
\hline Fear & $0.611 \pm 0.265$ & 0.025 & 5.320 & 0.025 & NS & & & \\
\hline Smile & NS & & & & $0.750 \pm 0.276$ & 0.009 & 7.353 & 0.009 \\
\hline Neutral & NS & & & & $0.811 \pm 0.289$ & 0.007 & 7.856 & 0.007 \\
\hline
\end{tabular}

Footnotes: Dependent variable is the average response time according to facial expression; NS, not significant.

trials, regardless of the type of facial expression. The regression model of the P300 latency $(F=7.629, d=1$, $P=0.008)$ was significant. There was a rather strong positive correlation between the P300 F3 latency and average response time $(r=0.703)$, indicating that the longer the P300 F3 latency, the greater the average response time.

The response times in negative facial expression trials were compared with those in neutral and positive facial expression trials. We tested whether the response time to the type of facial expression affected the P300 F3 and F4 latencies. As is shown in Table 3, all regression models were significant. Correlations of the F3 and F4 latencies with the response time were positive, indicating that the longer the F3 and F4 latencies, the slower the response performance. Interestingly, the P300 F3 latency significantly correlated with the average response time for negative facial expression trials such as annoyance, disgust, and fear. In contrast, the P300 F4 latency was not significantly associated with the response time in any of the trial types. Also, the P300 F4 latency significantly correlated with the average response time to facial expressions such as smiling, neutrality, and sadness, while correlation of the P300 F3 latency was insignificant. These results appear to be related to the lateralization of the neural responses in the DLPFC region according to the facial expression type. We focused on analyzing the F3 latency because interference effects of negative facial expressions compared to those of neutral or positive ones were greater for individuals with high anxiety. Finally, this result indicated that longer P300 F3 latencies were related to anxiety and associated with longer response times suggesting slower target identification.

ERP Activation Effect on the Processing Efficiency. The processing efficiency theory argues that higher anxiety is associated with the reduced performance efficiency during a demanding task, with more efforts and resources being expended to avoid actual decrements in the effectiveness or accuracy. At the neural level, the attentional control theory predicts that high anxiety will produce increased prefrontal cortical activation in order to achieve a given desirable level of the cognitive task performance. We examined whether high anxiety is associated with greater cerebral activity. Multiple regression analysis was performed using the STAI score as the dependent variable and the F3, F4, Cz, and Pz amplitudes of the P100 and $\mathrm{P} 300$ components as predictors. The regression model for the P100 amplitude was clearly not significant $(F=1.010, d=2, P=0.371)$, but the analogous model for the P300 amplitude was rather close to the level of significance $(F=2.511, d=2, P=0.091)$. Table 4 shows that the effects of anxiety were associated with conflicting characteristics of the amplitude at the F3 and F4 positions. The correlation coefficient for the F3 amplitude was negative, suggesting that the lower the F3 amplitude, the higher the STAI score. At the same time, the coefficient for the F4 amplitude was positive,

Table 4. Associations of the STAI score with the ERP amplitude variables using multiple linear regression analysis

T а б л и ц я 4. Зв'язки між оцінками за STAI та амплітудами компонентів пов'язаних із подією потенціалів, визначені 3 використанням аналізу множинної лінійної регресії

\begin{tabular}{lcc|c}
\hline & Variable & M s.e.m. & $P$ value \\
\hline F3 amplitude & & $86.875 \pm 43.918$ & 0.053 \\
F4 amplitude & $90.164 \pm 41.361$ & 0.034 \\
\hline
\end{tabular}

Footnote: Dependent variable is STAI score. 
indicating that the greater the F4 amplitude, the higher the STAI score. Thus, the opposite characteristics of the P300 latency were associated with higher anxiety in the DLPFC region of two hemispheres.

Finally, these results showed that higher STAI scores were associated with the ERP pattern having longer latencies and lower amplitudes at F3, whereas higher STAI score was associated with the shorter latency and greater amplitude of ERP component at F4.

The Performance Effectiveness and Anxiety. We also tested whether anxiety could adversely affect the performance effectiveness. The latter index was defined as the number of errors, which included cases where the participant responded to the wrong target, did not respond at all, or responded with a delay longer than $1500 \mathrm{msec}$. We examined whether the ERP latency to the target number predicted the smaller performance effectiveness. Multiple regression was estimated using a backward method of selection where the number of errors served as the dependent variable, and values of the P300 latency at each position (F3, F4, Cz, and Pz) were the predictors. In addition, single regression was calculated where the error count was the dependent variable, and the STAI score was the predictor.

The multiple regression model of the P300 latency $(F=1.450, d=2, P=0.244)$ and the single regression model of STAI score $(F=0.006, d=1, P=0.939)$ were both insignificant. These results indicate that the level of anxiety does not considerably affect the performance accuracy under MSIT conditions. The regression analyses also showed that the state of anxiety does not affect the performance effectiveness.

\section{DISCUSSION}

The goal of our study was to elucidate whether high anxiety impairs attentional inhibitory control and processing efficiency during the MSIT using ERP and behavioral response measurements. A few findings relevant to the initial hypotheses did emerge. First, our results indicated that the MSIT can be used as a valid technique for assessing emotion-related attentional inhibitory control related to anxiety. Second, the results also showed that the anxiety level is specifically associated with the ERP P300 latency in the DLPFC region. Higher anxiety was related to a longer latency of this wave at F3 but to a shorter latency at F4. Third, our results showed that the response times were different according to the type of the facial expression image used as a distracter in such a way that the response time to negative facial stimuli (e.g., annoyance, disgust, and fear) was affected by the P300 latency at F3, whereas this time to other face stimuli (e.g., neutral, smile, and sadness) was affected by the P300 latency at F4. Finally, the results showed that anxiety is oppositely associated with the ERP P300 amplitude in the DLPFC region. Higher anxiety was related to lower amplitude at F3 but to a greater amplitude at F4.

In previous studies, several different tasks (e.g., antisaccade, visual search, emotional spatial-cuing, and dot probe tasks) were used to assess the effects of anxiety on inhibition of distracting stimuli $[7,12,13,15$, 16]. These studies showed that highly anxious vs. less anxious individuals showed clearly impaired inhibition control and lower processing efficiency. However, the tasks used could not be claimed as process-pure ones that primarily reflect a single underlying process [34]. In our study, we used the MSIT [22], a technique that was not used previously to assess the effects of anxiety on inhibition of distracting stimuli. A task that required the interplay of emotions and attention to measure emotion-related attentional inhibitory control was needed in order to directly test any relationship between the above control and the anxiety level. Ebner [25] showed that the MSIT can measure interference effects of task-irrelevant faces on target numbers. This study, however, did not examine neural responses on the interference effects of task-irrelevant faces and on the target number.

Classical neurocognitive models of executive attentional control implicate the lateral PFC (DLPFC and VLPFC) and ACC in executive attentional control and, particularly, in the allocation of resources during conflicting or distracting situations [17-19]. If a significant neural response is present within the DLPFC and ACC areas during the MSIT, the task can be considered valid for measuring inhibition control of distracting stimuli. We found that the parameters of P300 at F3 and F4 in the DLPFC are related to the anxiety state. Thus, the MSIT is a rather valid method.

It is important to assess attentional processes as precisely and directly as possible in research on anxiety and performance. In previous studies, inhibition control and processing efficiency were examined only indirectly, by behavioral measures. Ansari et al. [12] showed that anxiety impairs attentional inhibitory control; the authors measured the latency of eye movements under distracting conditions. High-anxiety compared with low-anxiety individuals showed longer 
latencies of eye movements to the target. It was also found [13] that angry facial expressions were detected faster in a crowd of happy expressions, whereas happy faces were the slowest to be detected in a crowd of angry faces. Further, Fox et al. $[15,16]$ found that individuals in a high-anxiety state needed a significantly longer time to disengage attention from an angry face in an emotional spatial-cuing task compared to those with low anxiety. In general, these studies showed that higher anxiety leads to slower processing when trying to identify a target. In our study, the later-emerging P300 component was found to be associated with the number of correctly identified targets. If the latency of the P300 component is greater, it may be interpreted as slower identification of the target number. Interestingly, we found that higher anxiety estimates positively correlated with longer P300 latencies at F3 (left DLPFC) but not at F4 (right DLPFC), where shorter latencies of P300 were observed. The results appear to indicate lateraliztion of neural responses in the DLPFC region during the MSIT.

In several studies, it was also suggested that high anxiety slows down target identification [9]. The ERP latencies were found to correlate with the response time in the flanker task [35]. The relationship between neural responses assessed by ERPs and the response time provides clearer evidence of the relationship between anxiety and cognitive processing. Longer ERP latencies may be related to slower target identification and may consequently lead to longer response times. We, when trying to determine whether the longer ERP latency is accompanied by slowed target identification, analyzed the relationship between the ERP latency and response time and found that longer F3 and F4 latencies were associated with longer response times. We specially tested whether the type of facial expression used as a distracter affects target identification. The relationships between the F3 and F4 latencies of P300 and response times showed that the latter in the case of negative face distracter types (e.g., annoyance, disgust, and fear) were related only to the F3 latency, while this time at other face distracter types (e.g., neutral, smile, and sadness) was related exclusively to F4 latency. These results suggest that neural responses at the left DLPFC are closely related to the behavioral responses when negative facial expressions were presented. These neural responses reflect the difficulty in disengaging attention from the negative face distracter. The latency of P300 at F3 positively correlated with the response time. Thus, the latency of P300 at F3 may be a manifestation of emotion-related attentional in- hibitory control related to anxiety, and this parameter reflects impaired inhibition control.

The attentional control theory [1] suggests that high anxiety impairs the processing efficiency to a greater extent, as compared with the performance effectiveness. Several studies showed that high anxiety is associated with greater cerebral activity [36, 37]. Enhanced neural activation was assumed to reflect the use of greater efforts and/or resources as a compensatory strategy to achieve an adequate level of performance. However, trait anxiety is also associated with reduced DLPFC involvement when trying to inhibit distracter processing under conditions of low perceptual loading in the absence of a threat [9]. In our study, we found a slightly significant relationship between the anxiety level and the amplitude of P300 at F3 and F4. The reduced P300 amplitude at F3 and enhanced P300 amplitude at F4 are related to higher anxiety. When examining the response time and P300 latency related to anxiety in the left DLPFC (F3), we found that the anxiety state is associated with reduced and delayed neural activation in the left DLPFC, reflecting decreased attentional inhibitory control. The result is consistent with Bishop's findings [9].

We also investigated the adverse effects of anxiety on the performance effectiveness. The latter was measured as the number of errors during the MSIT. However, regression analysis showed no significant influence of the anxiety state on the performance effectiveness. Anxiety did not affect the performance accuracy, possibly due to the level of perceptual loading. There was a very low error rate across all participants, indicating that this task was relatively easy to perform due to a low perceptual loading. If so, the low base rate of errors may have precluded an adequate test of the relationship between the performance effectiveness and anxiety.

Notwithstanding these limitations, the results of our study allow us to suggest that anxiety impairs emotionrelated attentional inhibitory control in the DLPFC region, which was reflected in longer P300 latencies and lower P300 amplitudes at F3 and a longer response time to emotionally negative faces. The present ERP finding can help to improve our understanding of neural mechanisms involved in the effect of anxiety on the central executive functions and, in particular, on attentional inhibitory control. Further, these findings may be used as an index to assess the cognition performance for clinical and nonclinical anxiety disorders. We believe that future studies will examine whether these ERP findings extend to trait anxiety and state of anxiety. 
Acknowledgments: This work was financially supported by National Research Foundation of Korea (NRF) grant funded by the Korean government (MEST; No. 2010-0026833).

All testing procedures were in accordance with the Helsinki Declaration and with the ethical standards of the Responsible Committee on Human Experimentation (Institutional Review Board of the Severance Hospital). Written informed consent was obtained from all persons included in the study.

The authors, S. H. Seo, Ch. K. Lee, and S. K. Yoo, confirm that they have no conflict of interest.

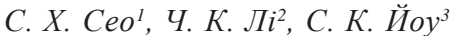

\section{НЕЙРОННІ КОРЕЛЯТИ РІВНЯ ТРИВОЖНОСТІ В ГАЛЬМІВНОМУ КОНТРОЛІ УВАГИ: ДОСЛІДЖЕННЯ З РЕЄСТРАЦІЮЮ ПОВ' ЯЗАНИХ ІЗ ПОДІЄЮ ПОТЕНЦІАЛІВ}

\author{
${ }^{1}$ Університет Кюнгнам, Тьюгсангнам (Республіка Корея). \\ ${ }^{2}$ Центр біоніки Корейського інституту наук і технології, \\ Сеул (Республіка Корея). \\ ${ }^{3}$ Медичний Коледж Університету Йонсей, Сеул \\ (Республіка Корея). \\ Р е $з$ ю м е
}

Ми досліджували вплив рівня тривожності на гальмівний контроль уваги з використанням реєстрації пов'язаних із подією потенціалів (ППП) та вимірювання часу реакції. 19 тестованих виконували мультистимульний тест 3 інтерференцією; як візуальні стимули застосовували зображення тризначних чисел та облич з емоціональними виразами. Параметри Р100 та Р300 компонентів ППП та час реакції брали до уваги для того, щоб визначити можливість асоційованості параметрів ППП та поведінкових відповідей з рівнем тривожності. Підвищена тривожність була асоційована 3 довшими латентними періодами та зниженою амплітудою компонента P300 у відведенні F3, тоді як такий рівень тривожності асоціювався 3 меншими величинами латентного періоду цієї ж самої хвилі та її вищою амплітудою у відведенні F4. Більший латентний період Р300 у відведенні F3 особливо чітко корелював із часом відповіді на цільове число на тлі облич із негативними виразами як відволікаючих факторів.

\section{REFERENCES}

1. M. W. Eysenck, N. Derakshan, R. Santos, and G. Calvo, "Anxiety and cognitive performance: Attentional control theory," Emotion, 7, 336-353 (2007).

2. J. M. G. Williams, F. N. Watts, C. MacLeod, and A. Mathews, Cognitive Psychology and Emotional Disorders, Wiley,
Chichester, Great Britain (1997).

3. J. M. Cisler and E. H. W. Koster, "Mechanisms of attentional biases towards threat in the anxiety disorders: an integrative review," Clin. Psychol. Rev., 30, No. 2, 203-216 (2010).

4. T. E. Moffitt, "The neuropsychology of conduct disorder," Dev. Psychopathol., 5, 135-151 (1993).

5. J. T. Nigg, "On inhibition/disinhibition in developmental psychopathology: Views from cognitive and personality psychology and a working inhibition taxonomy," Psychol. Bull., 126, 220-246 (2000).

6. M. W. Eysenck and N. Derakshan, "New perspectives in attentional control theory," Pers. Individ. Differ., 50, 955-960 (2011).

7. Y. Bar-Haim, D. Lamy, L. Pergamin, et al., "Threat-related attentional bias in anxious and nonanxious individuals: A meta-analytic study," Psychol. Bull., 133, 1-24 (2007).

8. N. Derakshan and M. W. Eysenck, "Anxiety, processing efficiency and cognitive performance: New developments from attentional control theory," Eur. Psychologist, 14, No. 2, 168176 (2009).

9. S. J. Bishop, "Trait anxiety and impoverished prefrontal control of attention," Nat. Neurosci., 12, No. 1, 92-98 (2009).

10. N. Derakshan, T. L. Ansari, L. Shoker, et al., "Anxiety and inhibition: An investigation using the antisaccade task," Exp. Psychol., 56, 48-55 (2009).

11. P. E. Hallet, "Primary and secondary saccades to goals defined by instructions," Vis. Res., 18, 1279-1296 (1978).

12. T. L. Ansari and N. Derakshan, "The neural correlates of impaired inhibitory control in anxiety," Neuropsychologia, 49, 1146-1153 (2011).

13. A. Öhman, D. Lundqvist, and F. Esteves, "The face in the crowd revisited: A threat advantage with schematic stimuli," J. Pers. Soc. Psychol., 80, 381-396 (2001).

14. C. H. Hansen and R. D. Hansen, "Finding the face in the crowd: An anger superiority effect," J. Pers. Soc. Psychol., 54, 917-924 (1988).

15. E. Fox, R. Russo, R. J. Bowles, and K. Dutton, "Do threatening stimuli draw or hold visual attention in sub-clinical anxiety?" J. Exp. Psychol.: General, 130, 681-700 (2001).

16. E. Fox, R. Russo, and K. Dutton, "Attentional bias for threat: Evidence for delayed disengagement from emotional faces," Cogn. Emot., 16, 355-379 (2002).

17. M. Botvinick, T. Braver, D. Barch, et al., "Conflict monitoring and cognitive control," Psychol. Rev., 108, No. 3, 624-652 (2001)

18. J. Duncan and A. M. Owen, "Common regions of the human frontal lobe recruited by diverse cognivtive demands," Trends Neurosci., 23, 475-483 (2000).

19. E. K. Miller and J. D. Cohen, "An integrative theory of prefrontal cortex function," Ann. Rev. Neurosci., 24, 67-202 (2001).

20. J. G. Kerns, J. D. Cohen, A. W. MacDonald, et al., "Anterior cingulate conflict monitoring and adjustments in control," Science, 303, 1023-1026 (2004).

21. S. Durston, M. C. Davidson, K. M. Thomas, et al., "Parametric manipulation of conflict and response competition using rapid mixed-trial event-related fMRI," NeuroImage, 20, 2135-2141 (2003)

22. G. Bush and L. M. Shin, "The multi-source interference task: An fMRI task that reliably activates the cingulo-frontalparietal cognitive/attention network," Nature Protocols, 1, 308-313 (2006). 
23. R. Jenkins, A. M. Burton, and A. W. Ellis, "Long-term effects of convert face recognition," Cognition, 86, 43-52 (2002).

24. R. Palermo and F. Rhodes, "Are you always on my mind? A review of how face perception and attention interact," Neuropsychologia, 45, 75-92 (2007).

25. N. C. Ebner and M. K. Johnson, "Age-group differences in interference from young and older emotional faces," Cogn. Emot., 24, No. 7, 1095-1116 (2010).

26. C. D. Spielberger, R. L. Gorsuch, and R. F. Lushene, Manual for the State-Trait Anxiety Inventory, Consulting Psychologists Press, Palo Alto (1970).

27. J. T. Kim, Relationship between Trait Anxiety and Sociability: Focused on STAI of Spielberger [Dissertation], Graduate School of Korea Univ., Seoul (1978).

28. N. C. Ebner, M. Riediger, and U. Lindenberger, "FACES-A database of facial expressions in young, middle-aged, and older women and men: Development and validation," Behav. Res. Methods (2009).

29. D. Hagemann, E. Naumann, and J. F. Thayer, "The quest for the EEG reference revisited: A glance from brain asymmetry research," Psychophysiology, 38, 847-857 (2001).

30. E. M. Mueller, S. G. Hofmann, D. L. Santesso, et al., "Electrophysiological evidence of attentional biases in social anxiety disorder," Psychol. Med., 39, No. 7, 1141-1152 (2009).

31. S. A. Hillyard and D. L. Wood, "Electrophysiological analysis of human brain function," in: Handbook of Behavioral Neurology, M. S. Gazzaniga (ed.), Plenum, New York (1979), pp. 345-378.

32. A. Moors and J. D. Houwer, "Automaticity: a theoretical and conceptual analysis," Psychol. Bull., 132, 297-326 (2006).

33. R. M. Shiffrin and W. Schneider, "Controlled and automatic human information processing: Perceptual learning, automatic attending and a general theory," Psychol. Rev., 84, 127-190 (1977).

34. S. B. Hutton and U. Ettinger, "The antisaccade task as a research tool in psychopathology: A critical review," Psychophysiology, 43, 302-313 (2006).

35. J. R. Folstein and C. Van Petten, "Influence of cognitive control and mismatch on the N2 component of the ERP: A review," Psychophysiology, 45, 152-170 (2008).

36. S. Righi, L. Mecacci, and M. P. Viggiano, "Anxiety, cognitive self-evaluation and performance: ERP correlates," $J$. Anxiety Disord., 23, 1132-1138 (2009).

37. A. N. Savostyanov, A. C. Tsai, M. Liou, et al., "EEG correlates of trait anxiety in the stop-signal paradigm," Neurosci. Lett., 449, 112-116 (2009). 